PHYSICAL REVIEW SPECIAL TOPICS - PHYSICS EDUCATION RESEARCH 6, 029902(E) (2010)

\title{
Erratum: Patterns, correlates, and reduction of homework copying [Phys. Rev. ST Phys. Educ. Res. 6, 010104 (2010)]
}

David J. Palazzo, Young-Jin Lee, Rasil Warnakulasooriya, and David E. Pritchard (Received 6 August 2010; published 21 September 2010)

DOI: 10.1103/PhysRevSTPER.6.029902 PACS number(s): 01.40.Fk, 01.40.Di, 01.40. - d, 01.50.H-, 99.10.Cd

This statement should be added to the Acknowledgements:

We thank both Effective Educational Technologies [18] and Pearson Education for providing us with log files of students' interactions with MasteringPhysics.com.

This reference should be added to the references.

[18] Effective Educational Technologies was the family company of DEP which developed both MyCybertutor, and MasteringPhysics. In 2006, Effective Educational Technologies was sold to Pearson Education, for whom DEP is a consultant. Privacy-protected log files of students' interactions with MasteringPhysics.com (and other Mastering products) can be obtained from Pearson for research purposes through Dr. Rasil Warnakulasooriya, Rasil.Warnakulasooriya@ pearson.com. 